\title{
Emotion as creative practice: Linking creativity and wellbeing through the history and sociology of emotion
}

\author{
Frederic Kiernan
}

\begin{abstract}
This article draws on recent developments in the history of emotion and the sociology of creativity to argue that emotions themselves may be viewed as creative practices. After an initial, broad overview of key historical and epistemological complexities in emotions research, it describes a framework for understanding emotion (and the history of emotion) proposed by Monique Scheer (2012), which is grounded in the practice theory of French sociologist Pierre Bourdieu. In Scheer's view, emotions should not be viewed as fundamentally internal physiological or psychological states, but as the practices to which those states are inextricably linked, and by which they are mobilized, named, communicated and regulated. The article then describes a sociological framework for understanding creativity proposed by Janet Chan (2016), which is also underpinned by Bourdieu's practice theory, and which posits that creativity is an inherent feature of all social action and may generate social change via institutionalized cultural practice or cultural revolt, the latter of which may itself take at least three forms. It then links Scheer's and Chan's frameworks together, explaining how, from this sociological perspective, emotions can be understood as creative practices, as embodied acts of thinking performed in habituated ways and which themselves generate change by doing different types of creative work. It proposes a new four-part framework for categorizing emotions as creative practices, based on Chan's framework for creativity: 1) emotion as institutionalized cultural practice; 2) emotion as cultural edgework; 3) emotion as cultural transcendence; and 4) emotion as cultural transformation. It concludes by suggesting that this framework provides an original and useful way of explaining the role of emotion in generating social and historical change, and of explaining the link between creativity and wellbeing from a sociological perspective.
\end{abstract}

Keywords: emotion, practice theory, Pierre Bourdieu, emotion as practice, history of emotions, creativity, sociology of creativity, wellbeing, creativity and wellbeing, emotions and change

\section{Introduction}

In a presentation at the Marconi Institute for Creativity (MIC) Conference, 2020, Vlad Glăveanu (2020b) observed that the power of creativity is precisely that of helping us reposition ourselves vis à vis the here and now of experience. In his recent writing about migrants from the perspectives of mobility studies and possibility studies, Glăveanu (2020a) also points to creativity's relevance to the broader study of emotion and affect. Drawing inspiration from Glăveanu, this article adopts his statement as the starting point for a sociologically oriented theoretical investigation of creativity and wellbeing by employing emotion as a conceptual stepping-stone linking the two.

Emotion is very often cited as a core element in definitions of wellbeing (Dodge et al., 2012). Two broad traditions of wellbeing research have addressed emotion in different ways (Ryan \& Deci, 2001; Henderson \& Knight, 2012; Huta, 2016). The hedonic tradition has tended to focus on 
pleasure attainment and pain avoidance, and therefore emphasizes happiness, positive affect, low negative affect, and satisfaction with life (Diener, 2009; Kahneman et al., 1991; Lyubomirsky \& Lepper, 1999). On the other hand, the eudaimonic tradition has emphasized meaning, selfrealization, positive psychological functioning and human development (Rogers, 1961; Ryff, 1989; Ryff \& Singer, 2008; Waterman et al., 2010; Vittersø, 2016). Most researchers now treat wellbeing as a multi-dimensional construct (Diener, 2009), with positive emotion often foregrounded as an essential defining feature, even if this is implied as a result of the cultivation of other factors (Seligman, 2011). Sociological approaches to the study of wellbeing have examined, for example, the link between social status and life satisfaction (Connolly \& Sevä, 2018), and the way adjacent concepts such as occupational prestige predict health, self-esteem, and job-satisfaction outcomes in various contexts (Treiman, 2013; Smith, 2004; Fujishiro et al., 2010). However, in part because of historical and disciplinary complexities in both emotions and creativity research (to be outlined in more detail below), the role of creativity and emotion in understanding wellbeing from a sociological perspective is still not well understood. Steve Derné (2017) has argued that sociologists of wellbeing are too heavily focused on suffering, and that moving away from topics such as pain and anguish towards discussions about how people define and experience wellbeing could provide fruitful avenues for further sociological research.

In thinking about creativity and its potential links with wellbeing, this article draws on a definition of emotion as practice developed by Monique Scheer (2012) in the nascent field of the history of emotion and synthesizes this with a framework for the sociology of creativity recently proposed by Janet Chan (2016) to argue that emotions can be viewed as creative practices. The article highlights multiple intersections between emotion and creativity to argue that emotions may be viewed as fundamentally creative acts, proposing a four-part framework for categorizing emotions as creative practices. The article concludes by suggesting that this framework provides an original and useful way of explaining the role of emotion in generating social and historical change, and of understanding the link between creativity and wellbeing from a sociological perspective.

\section{Research on emotion and creativity: Historical complexities}

The term "emotion" has historically been just one of several related terms referring to a much wider variety of phenomena than the scientific term "emotion" does nowadays. In the seventeenth century, the term "emotion" could refer to physical agitations of any kind, including those caused by the wind in the trees (Dixon, 2012). In the early nineteenth century, Thomas Brown, a professor of moral philosophy at the University of Edinburgh, merged a number of everyday concepts (including passion, sentiment, affection) into one scientific concept "emotion" (Dixon, 2003), but struggled to define what he meant by the term, writing, "Perhaps, if any definition of them [emotions] be possible, they may be defined to be vivid feelings, arising immediately from the consideration of objects, perceived, or remembered, or imagined, or from other prior emotions" (Brown, 1820/2010, 145-146). Some decades later, William James (1884) famously asked "What is an emotion?", reflecting not his engagement with an age-old conundrum, but rather, an attempt to define a relatively new psychological category in scientific discourse. For Thomas Dixon (2012), the transition of the term "emotion" into scientific discourse during the nineteenth century severed important links between emotion, morals and ethics which psychologists (Averill, 2009), sociologists (Harkness \& Hitlin, 2014) and historians (Boddice, 2018; 2019) have only relatively recently begun to reconnect. This is a project that resonates strongly with the objectives of this article. 
The term "emotion" continues to resist clear definition. Paul Kleinginna and Ann Kleinginna (1981) identified 92 definitions of "emotion"; almost three decades later, Carroll Izard's (2010) study of the many meanings and aspects of emotion explored the views of 35 distinguished scientists on emotion, finding that:

many psychological scientists and behavioral neuroscientists affirm that 'emotion' influences thinking, decision-making, actions, social relationships, well-being, and physical and mental health. Yet there is no consensus on a definition of the word 'emotion,' and the present data suggest that it cannot be defined as a unitary concept (p. 363).

Izard also found there was moderate support for the view that the term "emotion" is "ambiguous and has no status in science" (p. 367). A more recent study by Ursula Hess (2017) examined whether cognitive scientists view emotions as categorical or dimensional in nature, where a "categorical" definition of emotion would ascribe discrete states characterized by qualitatively different neural substrates, expressive reactions, action tendencies and feeling states, while a "dimensional" approach would define emotions according to degrees of valence and intensity. The findings were inconclusive. Hess wrote, "the answer to the question of whether emotions are categorical depends to some degree on why this question is asked" (p. 121). In other words, cognitive scientists not only disagree about how to define emotion, but also about what type of scientific category "emotion" even falls into.

Research on emotions across various disciplines (primarily the life sciences and anthropology) has gradually been corralled into two main paradigms, identifiable by universalist and social-constructionist discourses on emotion (Biess \& Gross, 2014; Plamper, 2015), with the latter being discussed further below. In the universalist camp, scholars have argued that at least some "basic" emotions are universally experienced by all humans in the same way (Ekman et al., 1969; Ekman \& Friesen, 1971; Ekman, 1999; 2007). This has encouraged psychological approaches to the study of the link between emotions and creativity that focus primarily on individual-level variables (Isen et al., 1987; Russ, 1993; Averill, 1999; Radford, 2004; Ivcevic \& Hoffmann, 2017). Scholars working in this paradigm have tended to investigate the link between emotion and creativity by isolating variables pertaining to either or both concepts and then testing how they interact (Russ, 2020). These approaches have shown emotion (Ivcevic \& Hoffmann, 2019), affect (Isen et al., 1987) and mood (Baas, 2019) to be crucial to creativity, where creativity is usually treated as the production of a product deemed both novel and useful or appropriate in a particular context (Cropley, 2011). Different definitions of creativity have typically placed varying degrees of emphasis on the person, process, or product as elements of creativity (Runco \& Jaeger, 2012), while a fourth p, "press" (i.e., the pressure of the environment) has also been given attention (Rhodes, 1961), taking the study of creativity into domains previously viewed as irrelevant, such as education and business (Cropley, 2011). Recent research has further broadened the focus in psychological creativity studies by showing how creativity can be viewed as "distributed", that is, existing across and between multiple actors, materials and domains (Glăveanu, 2014). When relationships are taken as the unit of analysis rather than isolated individuals, creativity can be viewed as a "socio-cultural act" (Glăveanu, 2015).

Research on the role of emotion in generating social and historical change is still relatively new, with emotions often being treated as responses to, or by-products of, change processes, rather than facilitators of them (Barclay, 2017). However, historians of emotion have begun to view emotion as social structure rather than as something embedded in it (Barclay, 2017, p. 4), 
thereby providing new frameworks for understanding the links between emotion and social change. Barbara Rosenwein's (2006) concept of "emotional communities" emphasizes how social groups can share norms of emotional valuation and expression, and in so doing she ties change to language and society. Katie Barclay (2011) has suggested that emotions, especially love, can reproduce particular forms of social order, and she uses a Foucauldian approach to argue that emotions facilitate incremental change by way of reiterative processes of negotiation. William Reddy's (2001; 2008) concept of "emotional regimes" (2001, p. 29, and outlined further below) describes normative standards for emotional behavior that reinforce political power, arguing that change occurs through communities of resistance which also comprise "emotional refuges" (2001, p. 29). (For a useful overview of recent theoretical work on emotion and change, see Barclay, 2017). In what follows, I will propose an alternative explanation for the role of emotion in generating social and historical change.

The most explicit recent attempt to define emotions as creative in psychology has been made by James R. Averill (1999; 2009), who has proposed that the standard criteria for creativity (which he states are novelty, effectiveness and authenticity) apply not only to intellectual and artistic "responses" but also to emotional ones, and thus, he frames emotions "as creative products" (2009, p. 251). In this vein, he argues that characteristics commonly associated with spiritual experiences (meaning, vitality and connectedness) apply to emotionally creative responses (Averill, 1999). This approach does much to link the concepts of ethics, emotions and creativity together, by anchoring the functional and adaptive aspects of emotional behavior to an individual's moral and ethical frameworks and belief systems. He also observes that the way emotional performances unfold is determined much more by social scripts than by evolutionary or biological drivers. Using the example of grief, he writes, "From a social perspective, grief is a role that societies create in order to facilitate transition following bereavement, and that people may enact with greater or lesser involvement... biology only sets the stage; it does not write the script" (Averill, 2009, p. 251; see also Averill \& Nunley, 1988). However, while clearly grounded in a social-constructionist view of emotion, his approach frames emotions as fundamentally individual responses within a trigger-response dialectic, as "syndromes, that is, coordinated sets of responses to situations appraised as beneficial or harmful to the person" (Averill, 2009, p. 250). This definition does not adequately account for the possibility that emotions are not always spontaneous responses to situations, but may indeed be deliberately evoked and strategically performed, as will be argued below. His approach also hinges on a definition of creativity as novelty, effectiveness and authenticity, which, as noted above, has recently been contested (Glăveanu, 2015; 2020b).

Sociological and anthropological research on emotion increased significantly during the last three decades of the twentieth century (Stets \& Turner, 2014b) and has often contested the claim that emotions are universally experienced by all humans the same way (Rosaldo, 1980; Lutz, 1988). Definitions of emotion in sociology have proposed that emotions are senses that signal what is personally relevant about surrounding social events (Hochschild, 1983); or have considered emotions in terms of four interdependent factors: physiology, cognition, expression and labelling (Thoits, 1984); or, more recently, have framed emotions somewhat broadly as "responses to events that are linked with corporeal manifestations" (Lively \& Heise, 2014, p. 68). These approaches share a key focus on the interdependent relationship between emotions and the cultural and structural relationships in which they occur, showing how they are both shaped by and reify those arrangements (Lively \& Weed, 2016, p. 76; Stets \& Turner, 2014a). The practice theory of French sociologist Pierre Bourdieu $(1977 ; 1986 ; 1990)$ has also been influential in shaping sociological approaches to emotions research, for example, in discussions about 
"emotional capital" (Erickson \& Cottingham, 2014), or "emotional habitus" (Burkitt, 1997), terms which I will clarify below. However, it was actually in the field of the history of emotion, not sociology, that Monique Scheer (2012) first proposed that emotions may be understood as a kind of practice in the Bourdieuian sense. Together with Chan's (2016) framework for the sociology of creativity, to be outlined further below, Scheer's theoretical contribution represents one of two crucial pillars to the argument being made in this article: that emotions can be viewed as creative practices.

In sociology, creativity has also been a marginal topic historically, with the field of creativity research being dominated until recently by psychological and philosophical approaches (Paul \& Kaufman, 2014). While Weber's notion of charismatic leadership, Durkheim's "collective effervescence", and Marx's "active and creative subject" all made use of the concept of creativity in some way (Chan, 2016), "the tendency to marginalize creativity was common to sociology in all the main national traditions" until recent years (Domingues, 2000, p. 468). Chan (2016) has proposed that the two theorists who stand out as having made significant advances in the sociology of creativity are Hans Joas and Pierre Bourdieu. Joas (1996) drew on models of creative problem solving proposed by American pragmatists such as John Dewey, William James, Charles Peirce and G. H. Mead to theorize creativity as a distinct model of social action alongside habitual rational and normatively oriented action. He proposed that creativity is what happens when habits are interrupted, where such interruptions lead the actor to reconstruct their context through new ways of acting and thinking. Drawing inspiration from Joas, Benjamin Dalton (2004) nonetheless challenges his position in three key aspects, asserting that: 1) the duality between creativity and habit that Joas endorses is misleading, and human action can in fact be simultaneously habitual and creative; 2) Joas ignores to his detriment a contemporary strand of sociological theorizing based on Bourdieu's concept of habitus which can explain the simultaneous presence of habitual and creative elements in all human action; and 3) the incorporation of creative action into sociological theories of agency requires recognizing that creativity and habit cannot be viewed as separate types of action. As Dalton (2004) writes,

Creativity is not simply the impulsive action of an inherently creative agent, a reaction to the interruption of previously successful routines, or a restrictive set of strategies available to the habituated actor. It also rests on the perfection of routine and the practical difficulties of action (pp. 604-605).

Artists can, for example, produce "good art", which is deemed creative by the art world, without ever consciously attempting to be creative or experiencing interruptions to their routines; indeed, it is often the cultivation of routine that supports their production of creative work (Chan 2016, p. 647). Thus, even when habits or routines are successful, actors may be driven by mere boredom or exhaustion to alter or experiment with them. From this perspective, habits, routines and norms are not static; they are developed over time and can generate change, and are thus an ethical and political direction that actors may or may not move in.

The claim that habitual and creative elements simultaneously exist in all human action leads Chan (2016) to point out that the sociology of creativity is therefore premised not on the idea that specific people or processes are creative per se, but on the idea that creative social products are deemed creative (or not) by relevant critical communities according to domain-specific criteria. Chan's framework for the sociology of creativity, which draws primarily on Bourdieu's practice theory while incorporating ideas from Joas, Dalton and others, thus forms the second key pillar, alongside Scheer's (2012) framework of emotion as practice, in my argument that emotions may 
be viewed as creative practices in this sociological sense. The two frameworks will now be set out in more detail before I make an attempt at their synthesis.

\section{Monique Scheer's framework for understanding emotion as practice}

Monique Scheer $(2012)$ has argued that Bourdieu's $(1977 ; 1990)$ practice theory can be used to redefine "emotion" and to rethink the relationship between emotion, body and mind. In so doing, she provided an important framework for doing the history of emotion which has since been adopted by historians working across a range of periods (Davison et al., 2018). Bourdieu argued that practices are unconscious strategies that actors use to position themselves within a social field by investing capital and seeking more capital (Robbins, 2014). Here, "field" refers to broad and sometimes overlapping social spaces such as family, work, or the legal system, which influence the way things are said and done in that space, and which shape the way those sayings and doings are likely to be interpreted by others (Thomson, 2014). "Capital" refers to various types of resource, which all together take a symbolic form, but which can be classified into different types (for example, economic, social and cultural capital); as such, capital includes things like the knowledge of what constitutes appropriate behavior in a certain context (Bourdieu, 1986; 1990, pp. 66-68; Moore, 2014).

Practices are strategic social action and have been defined as "an organized constellation of different people's activities" based on "practical rules ... teleoaffective structures, and general understandings" (Schatzki, 2012, pp. 13, 15). Practices arise from the bodily knowledge that is accumulated as actors go about their social lives, much like the bodily knowledge that skilled drivers draw upon when navigating traffic in almost-automatic (that is, habituated) yet also improvised fashion, or which musicians with some degree of proficiency use when playing their instrument. For Bourdieu (1990), this knowledge is stored in what he terms the "habitus", which is "embodied history, internalized as second nature and so forgotten as history - [it] is the active presence of the whole past of which it is the product" (p. 56), or, in other words, a durable but evolving tendency to act the same way in similar situations (Maton, 2014). "Habitus" thus refers to a general disposition for intelligent and strategic action, which is never perfectly prescriptive, meaning that it does not lock actors into robotic ways of being, even though it is the product of past experiences and socialization (Dalton, 2004, p. 612). One's actions in the world, even when deeply habituated, must always be tempered by the demands of the field, and as such, the imperfect alignment between habitus and field requires innovation in the carrying forth of social action. For this reason, Bourdieu described the habitus as "the intentionless invention of regulated improvisation" (Bourdieu, 1990, p. 57).

Members of a particular ethnic or cultural group will usually learn particular values, dispositions, ways of thinking, categorizing and even speaking that are acceptable within a field. The habitus generates strategies and actions (i.e., practices) that inform and guide how people maximize their capital in a field, and for this reason, practices arise from the interplay between habitus, capital and field. Practices can be learned and unlearned, often but not always unwittingly, and they are sustained by reiteration (Davison et al., 2018). Practices therefore fall in and out of use in different social and historical contexts, and in Bourdieu's theory the shared embodied dispositions in the habitus are what mark people as members of a culture (Chan 2016, p. 645). For example, in the past the act of tipping one's hat may have felt like an almost entirely automatic and natural way to greet somebody. From the perspective of Bourdieu's practice theory, this act can be viewed as an investment of the hat-tipper's knowledge of the appropriate way to act in a particular context, expressed in a habituated, embodied and performed way, and which serves the strategic purpose of communicating the message "I greet you". Nowadays, the 
practice may seem rather anachronistic because its strategic value has been reduced in many fields if not completely lost.

Scheer (2012) argued that emotions can be understood as precisely the same type of thing: strategies for navigating social space, which may be learned or unlearned, and which involve engagements not just of internal physiological systems but also movements of the body and even the conscription of objects from the material environment (like one's hat) into a learned performance of emotion. The performance of emotion may thus feel almost entirely automatic and natural to the performer, but it is in fact deeply culturally and socially inflected. Scheer's argument closely parallels that made by the philosophers of science Paul E. Griffiths and Andrea Scarantino (2009), who claim that emotions are "situated", meaning that they are: designed to function in a social context; forms of skillful engagement with the world; scaffolded by the environment; and dynamically coupled to the environment which both influences and is influenced by the unfolding emotion (pp. 437-438). Research in the fields of embodied cognitive science, enactivism, ecological dynamics and ecological psychology also supports the idea that the body is a knowing, mindful entity that stores past experiences in habituated, practical processes (Gallagher, 2005; Sutton et al., 2011; Bergen, 2012; Kimmel et al., 2018), and has proposed that cognition should be described in terms of agent-environment dynamics rather than in terms of computation and representation (Chemero, 2009). These theoretical developments are grounded in different epistemological frameworks than the sociology of Bourdieu's practice theory, and the current article is not attempting to map those concepts from one discipline to another; however, the key messages of these approaches are very similar: along with the brain, the body knows, remembers, and thinks.

Scheer (2012) thus argues that emotions are not something that happen to us so much as something that we do, and for this reason, emotions are not timeless, ahistorical states of being, but historically and socially specific acts of consciousness performed by a thinking, situated body-and-mind that is accumulating knowledge of how to navigate its social environment all the time. Scheer's framework of emotion as practice also locates emotion not strictly within the body, but instead in the practices that link habitus, capital and field, which exist both within and between the body and its environment. Because of this, Scheer uses the terms "feeling" and "emotion" interchangeably (and for this reason I will as well in this article), while acknowledging that scholars working in the universalist-psychological paradigm usually do not (Scheer, 2012, p. 198). Emotions can thus be induced, scaffolded, manipulated and diffused through practice, and require reiteration to maintain their integrity (Davison et al., 2018). Critics of practice theory as it applies to emotions have proposed that it struggles to deal with breaks in societal norms, suggesting that affect theory and psychoanalysis have proposed better models for explaining these issues (see the discussion of this issue in Trigg, 2014). However, the dependency of practices on iteration does allow for shifts in performance and interactions within a field, thereby opening up the opportunity for change leading to new logics of practice (Davison et al., 2018). Below, I will take this point further to argue that emotions are creative practices, thus providing an alternative explanation for the role of emotion in generating social and historical change that relies not on the opportunities for change that exist between iterations of practice, but because, as Chan (2016) has proposed, practices are themselves creative. Scheer's framework has thus been influential in advancing the history of emotion because it expands thinking beyond the long-held assumption that emotions are fundamentally internal experiences and thus beyond the reach of historians. It has allowed historians to examine the traces of emotion as practice left behind in objects, texts and artifacts, to see how they have fallen in and out of use over time and place, and to understand how emotions have served different strategic purposes, as practices do. 


\section{Janet Chan's framework for the sociology of creativity}

Chan (2016) argues that Bourdieu's theory of practice, with some minor modifications suggested by Dalton (2004), provides a solid foundation for a useful sociology of creativity. She proposes that while creativity is an inherent feature of social action arising from the necessarily partly improvised strategies generated by the habitus, the form creativity takes depends on the nature of the field and the intentions of the actors in it. Chan writes,

the necessity to innovate is part of an overarching habitus that people share, regardless of their field of practice. When faced with obstacles and difficulties, people may follow the habituated way of dealing with problems allowed in their field, or they may question or challenge these accepted ways ... (pp. 647, italics in original).

If a field is stable and actors are in a comfortable position, creativity can take the form of institutionalized cultural practice, while if a field is rapidly changing or one's position in the field is uncomfortable, creativity can emerge as cultural revolt, which will be described below.

For Chan (2016), creativity as institutionalized cultural practice is the typical form of creativity produced by artists, scientists and workers in creative fields who simply do their work well. This form of creativity may seem counterintuitive to those more familiar with pragmatist approaches to understanding creativity, which often treat creativity and habit as oxymoronic and which tend to emphasize novelty rather than value as evidence of creativity (Dalton, 2004; Rehn \& De Cock, 2009). However, by most definitions, novelty alone is not a sufficient condition for creativity (Cropley, 2011), meaning that, in some contexts, the ability to identify and retrieve value from the already-existing may also be considered creative (Rehn \& De Cock, 2009). Creativity as institutionalized cultural practice places less emphasis on the production of novelty and originality as elements of creativity, even though it can facilitate gradual, valuable change, and it also downplays "thinking outside the box" as the pathway to creative work (Rehn \& De Cock, 2009, p. 223); instead, it places greater emphasis on the cultivation of habits, the achievement of incremental gains and the gradual perfection of routines leading to new social (e.g. artistic, scientific) products judged as "creative" by critical communities according to domain-specific standards of excellence. From this perspective, cultures marked by rhetorics of novelty, experimentation and the valorization of risk-taking, and particularly those framed by modernist narratives of progress and capitalist development (Rehn \& De Cock, 2009) may actually be less likely to lead to the production of great art, science and literature than the orthodox strategy of simply doing one's job well (Chan, 2016, pp. 649-650).

Creativity as cultural revolt can emerge when an actor finds themselves in a difficult or uncomfortable position in a field, as a search for "control over emergence" or a bid for radical sovereignty (Lippens, 2012). For Chan (2016), this control over emergence can take at least three forms: cultural edgework, cultural transcendence, and cultural transformation. Drawing on Stephen Lyng's (1990) ethnographic foundation, Chan proposes that edgework occurs when actors seek to push or negotiate the boundaries between fields. This is often characterized by high-risk activities such as extreme sports, drug-taking, and high-risk sexual behavior, where boundaries such as life/death and health/illness are negotiated. But, working at the cutting edge of one's artistic or scientific field can also entail such negotiation and risk. Edgework thus generates a sense of authenticity and hyperreality, as a pathway to "objective reality uncontaminated by subjective cognition" that feels more "real" than real life (Lyng, 1990, p. 449). Edgework thus requires a high degree of skill as well as great trust in one's habitus, because the closer actors 
come to the edge, the more the habitus recedes and agency is liberated, which can account for the intense feelings of self-determination that edgeworkers report (Lyng, 1990, p. 453). However, while edgework, as a form of cultural revolt, can renegotiate boundaries between fields and thus do creative work, it is not a guaranteed pathway to creativity, because a failure to navigate its inherent risks successfully can have potentially extreme negative consequences (Chan, 2016, p. 654).

Cultural transcendence involves actors seeking to go deeper into a field to reinterpret it. This "occurs in and through detached reflection, decision and existential choice" (Lippens, 2012, p. 354), and is neither about the risk-taking of edgework nor about following traditions or conventional practices. Cultural transcendence, for Chan (2016), occurs through the solitude of being immersed in focused work, and paradoxically involves finding "more" by giving things up. It is therefore characterized in part by a grueling but gratifying search for meaning, order and unity. The creativity of this process occurs through the exchange of old meanings for new ones, resulting in new interpretations of the familiar.

Lastly, cultural transformation occurs as a form of creativity when actors seek to recreate (rather than reinterpret or renegotiate the boundaries of) a field. This involves bringing "newness into the world" (Lippens, 2012, p. 354, italics in original) by engaging with and transforming the field and its laws and codes that currently exist, without separating oneself from them. Chan (2016, p. 657) cites Gustave Flaubert as an example from the literary field of this kind of creativity through cultural transformation. Flaubert treated the seemingly mundane trivialities of everyday life with exceptional refinement and in a "flawless style ... as a result, his initial impotence turns into an extraordinary creation" (Dubois, 2000, p. 99). Cultural transformation can also occur as a result of encounters with different cultures, whereby fresh ideas can be adopted and adapted to suit a local environment, as in, for example, the adoption of Japanese aesthetics by architect Frank Lloyd Wright and their transformation into a "new unity" (Oiyama, 2013, p. 408). Chan's Bourdieuian sociology of creativity thus allows for creativity to take a variety of forms within the two main strands of institutionalized cultural practice and cultural revolt, which arise from the necessarily innovatory strategies of an imperfectly prescriptive habitus. In what follows I will attempt to synthesize the above described Bourdieuian frameworks for emotion and creativity in order to argue that emotions themselves may be viewed as creative practices.

\section{Emotion as creative practice}

Emotions may be viewed as creative practices in the Bourdieuian sense because emotions have a creative element that takes a practical form, as institutionalized cultural practice or cultural revolt, and in so doing, emotions do creative work. Because, for Chan (2016), the sociology of creativity focuses not on creative people or processes but on creative products that must be deemed creative by relevant knowledgeable communities, the creative element of emotion as practice is measured by the response of the relevant community to the products of an emotional performance, which is itself shaped by the agency of the actor and their creative decisions regarding an emotion's practical manifestation (e.g. its context, manner, media and timing). I argue that emotion as creative practice may take at least four forms, based on Chan's classifying categories for the sociology of creativity: 1) emotion as institutionalized cultural practice, when a field is stable or actors are in a comfortable position; or, emotion as cultural revolt, when a field is unstable or actors are in a difficult or uncomfortable position in a field, which takes the form of 2) cultural edgework; 3) cultural transcendence; or, 4) cultural transformation. And, because the form of the emotion changes in accordance with its practical manifestation, the emotion itself substantively changes, even if its name does not. An emotion may take different forms 
depending on how the emotion is practically oriented, and the emotion may do creative work in different ways leading to different social outcomes. To demonstrate this, and in accordance with the aim of this article to explore the link between creativity and wellbeing, I will apply the concept of happiness to each of the four categories described below, while also giving examples of how the creativity of other emotions can be understood using this framework.

Note that the argument being made here is that emotions are creative practices, but not necessarily the reverse; creative practices may or may not be emotions, and this line of reasoning may warrant further investigation elsewhere. The argument is, rather, that to feel is to do creative work, and that by illuminating the creative element of emotion, emotion as creative practice can provide a new way of explaining the role of emotion in generating social change and provide a useful link between creativity and wellbeing from a sociological perspective. And, because Scheer's framework of emotion as practice does not treat emotions as distinct from, or as byproducts of, social action, but rather as practical forms of engagement with the world, when coupled with Chan's (2016) Bourdieuian sociology of creativity emotion as practice can provide new insights into why people may engage in certain practices in order to feel, or avoid them in order not to. People may strategically evoke emotions or avoid doing them precisely because feeling does particular kinds of creative work. This, in turn, means that to feel involves varying degrees of risk, uncertainty and effort, and brings about different kinds of social change (Frevert et al., 2014; Davison et al., 2018; Eitler et al., 2014).

\section{Emotion as institutionalized cultural practice}

As Chan (2016) has proposed, when a field is stable or actors are in a comfortable position, creativity can take the form of institutionalized cultural practice. In such contexts, creativity appears not as "thinking outside the box" but as incremental change facilitated by routine practice (e.g. the gradual perfection or refinement of routine) leading to products deemed excellent by a knowledgeable community according to domain-specific standards. Emotion may take the form of institutionalized cultural practice. Different societies and social groups value emotions in different ways, encouraging and cultivating particular emotions in members of the group while discouraging other emotions (Reddy, 2001; Rosenwein, 2006). Socially sanctioned or appropriate emotions may be viewed as strategically valuable or desirable in one field, while being of lesser value in another field. Where an emotion is highly valued, the habitus will be oriented towards strategies (practices) that will cultivate it, and the success of the actor's work will depend on the domain-specific standards by which the emotional performance is judged.

From this Bourdieuian perspective, an emotion such as happiness may be viewed not strictly as a physiological or psychological state different in nature from, for example, surprise or disgust, but rather an institutionalized cultural practice to which physiological and psychological states are linked, and of which they are the result, and through the reiteration of which they are cultivated. Darrin McMahon's (2006) sweeping study of the history of happiness has traced, for example, the development of happiness over two thousand years. He argues that happiness was not widely viewed as something that people could or should achieve during their lifetime (as opposed to the hereafter) until the Enlightenment, and that this humanistic shift led to the consecration of happiness in the Declaration of Independence and France's Declaration of the Rights of Man. This fundamental change in expectations meant that "by the end of the eighteenth century ... happiness could claim widespread recognition as a motivating ideal" (McMahon, 2006, p. 13), which, in turn, has led to a modern search for happiness that has generated both new pleasures as well as new forms of pain. The latter has included, for example, gendered experiences of unhappiness in modern marriages, and the weaponization of happiness against 
feminists as "killjoys" as they attempt to direct attention towards examples of sexism (Ahmed, 2010). For Ehrenreich (2010), happiness as a motivating ideal has encouraged a cult of positive thinking whose obverse effects have included feelings of failure when succumbing to moments of grief or misery, guilt about not always being happy enough, and even claims by health professionals that Ehrenreich's anger in response to her breast cancer diagnosis was unhealthy and dangerous. When viewed through a Bourdieuian lens, happiness can be understood as an institutionalized cultural practice, whose performance is oriented in accordance with the values, norms and ethical frameworks internalized in the habitus of the actor in a given social or historical context and measured against the domain-specific standards in a field.

This is not to say that happiness is always an institutionalized cultural practice; in what follows I will suggest that there are other ways to be happy. I argue, rather, that when an emotion is highly valued in a field, the habitus is oriented towards strategies for attaining it, and when the field itself is stable or an actor's position is comfortable, these strategies can take the form of institutionalized cultural practice. The commercial slogans and happiness rhetoric of Coca Cola's various campaigns, from "Things Go Better with Coke" in 1963 to "Open Happiness" in 2009 (Ryan, 2019), or McDonalds reportedly spending $\$ 1.37$ billion in advertising the year of their " $\mathrm{I}^{\prime} \mathrm{m}$ Lovin' It" campaign (Schultz, 2019), illustrate how those with sufficient investing power in a field can generate value from an emotion by promising certain types of experience linked to specific practices which in these cases unsurprisingly include purchasing the product. The emotion thus becomes a collection of habituated activities arising from a habitus socialized to view happiness as desirable and valuable, requiring sustained effort, cultivation and practice to fine-tune, and whose performance is geared towards meeting domain-specific standards of excellence (for example, by crafting conspicuous public displays of happiness on social media or at social gatherings). The emotion may thus be viewed as an institutionalized cultural practice as defined by Chan (2016) and therefore, in this regard, as creative.

Any emotion can become an institutionalized cultural practice. Grief, for example, may be viewed this way in certain contexts, since the psychological and physiological manifestations of the emotion are tied to and given shape by specific culturally and socially inflected practices (Barclay, 2016). Such practices not only serve the purpose of expressing individual feelings of grief, but they also guide the performance and thus the experience of grief itself in accordance with domain-specific standards. These standards often vary across time and place (Averill, 2009). They may, for example, entail extended periods of public ritual involving specific mourning garments and musical or other cultural practices (Jalland, 1996; Maiello, 2005; Agawu, 1988; Racy, 1986). Or, as Paul Rosenblatt (2004) has observed, in cultures where the time available for solemn contemplation is more restricted, these standards may allow only for the rather unceremonious practice of "grieving while driving" (p. 679). Importantly, however, these standards and norms are not fixed; they are gradually altered and fine-tuned, and thus by their very doing they may change.

The concept of emotion as institutionalized cultural practice thus aligns in many ways with Reddy's $(2001 ; 2008)$ concept of "emotional regimes", which he defines as "normative emotional styles that are backed up by socially enacted rewards and penalties" (2008, p. 96). This concept is useful for explaining how political regimes can rely on emotion regulation as a coercive and even oppressive tool, threatening sanctions of varying degrees to compel people into hiding improper responses to normative emotional expressions. He thereby provides additional links between emotion, ethics and political power, which raise the important question of how free we really are to feel what we feel. However, while acknowledging that emotion as institutionalized cultural practice may indeed function as a coercive political tool, my purpose here is to 
emphasize that, insofar as the concept of emotion as institutionalized cultural practice reflects Reddy's emotional regimes, emotional regimes are themselves creative and change-generating. I suggest that the concept of emotion as institutionalized cultural practice provides an alternative explanation for how emotional regimes actually develop and why they are not fixed or static, but dynamic and changing.

From a sociological perspective, if actors are in a comfortable position in a field, or if the field is stable, an emotion may take on the creative form of an institutionalized cultural practice; however, if actors find themselves in a difficult or uncomfortable position in a field, or if the field is unstable, emotion may emerge as cultural revolt in one of three forms: cultural edgework, cultural transcendence, or cultural transformation. Each of these will be examined next in turn.

\section{Emotion as cultural edgework}

To recall, edgework is a sociological classifying category for voluntary risk-taking through activities that have a "clearly observable threat to one's physical or mental well-being or one's sense of an ordered existence" (Lyng, 1990, p. 857), and this, for Chan (2016), constitutes a sociological category of creativity. Chan's and Lyng's accounts of edgework already make clear links to emotion, by reference to feelings of fear and nervousness that usually arise during the anticipatory phases of edgework, which then give way to feelings of exhilaration and omnipotence (Lyng, 1990, p. 860). At the peak of the experience edgeworkers often report that their perceptual field becomes highly focused, with background factors receding from view and time passing either much faster or slower than usual (Lyng, 1990, p. 861). Edgework is thus closely linked with physiological and perceptual changes and feeling states in sociological literature.

Because the practice of edgework can take many forms (extreme sports, business entrepreneurship, wartime combat, drug experimentation, creative arts, and others), there is no unifying emotion that all edgeworkers experience, and in this sense it is somewhat analogous to Mihaly Csikszentmihalyi's (2014) conception of "flow". However, edgework differs from flow by virtue of edgework's extremeness (Lyng, 1990, p. 863). Edgework experiences are linked to notions of self-realization, self-actualization and self-determination. Lyng (1990) writes, "In the pure form of edgework, individuals experience themselves as instinctively acting entities, which leaves them with a purified and magnified sense of self" (p. 860). Edgework experiences arise from practices that push or negotiate the boundaries between fields through impulsive, anarchic and spontaneous social action, and edgework thus seems to be antithetical to role behavior in the institutional domain, where institutional practices are marked by constraint and normative control. Edgework practices are thus typically associated with excitement in a broad sense, although this does not necessarily always mean high physiological arousal. Activities that push the boundaries or limits between fields may induce the feeling states described above while also serving the purpose of slowing down the mind, as in, for example, the high-risk and high-skill activity of voluntarily attempting to survive in the wilderness, where creative work at the (e.g. geographical) boundaries of a field can be motivated by excitement as well as the desire "to slow my mind down", "to disengage from normal life", and "to get away from authority" (Ewert, 1994, p. 14).

The emotion "happiness" could therefore ostensibly overlap in some ways with the concept of edgework, given that the feeling of being one's "authentic self" is usually considered to be a key ingredient in popular conceptions of happiness (Seligman, 2002), although this version of happiness would be different in many ways from the routine institutionalized cultural practices described in the previous section. Emotion as cultural edgework is mobilized, named, 
communicated and regulated by practices at the boundaries between fields, and thus edgework does its creative work by linking factors such as political-economic variables with individual sensations and feelings (Lyng, 1990). Chan (2016) also drew upon Ronnie Lippens's (2012) idea of Radical Sovereignty Type 1 (pp. 353-354) in her formulation of edgework. For Lippens, this kind of creative work occurs where "the self unrelentingly flees all code and all law, immersing and indeed dissolving itself, i.e. its own coded self, in the sheer potential of life, and even beyond, into the sheer vital matter of earth ... In short: transgression" (p. 353-354, italics in original). Using the example of Jackson Pollock's painting Full Fathom Five (1947), Lippens shows how Pollock reached beyond the realm of law and code that says "you be this, or that", or "you be a self with particular features and characteristics", into a domain where he could encounter "the sheer energetic potential of yet-unformed matter" (pp. 355-356). Words that name and practices that shape such experiences, and which coalesce in a dynamic relationship between a thinking body's sensations and feelings and its environment, will vary across time and place, but they may nevertheless be linked by the underlying sociological concept of edgework as a particular form of creative practice at the boundaries between fields.

\section{Emotion as cultural transcendence}

Emotion as practice may facilitate the movement of an actor so deeply into a field that the actor reinterprets it. For Chan (2016), this is a category of creative work in sociology because it generates new perspectives on the familiar. For Lippens (2012), this work (which he named Radical Sovereignty Type 2) takes the form of "radically detached and equally relentless reflection" (p. 354), facilitating the exchange of old meanings for new ones, and generating new perspectives without changing or transforming a field per se.

A good example of such creative work taking the form of an emotional practice is mindfulness. There is now extensive literature on the practice and a variety of approaches to doing it, but many practitioners have drawn on Buddhist philosophy and the writings of the Dalai Lama to treat mindfulness as the "science of the mind" (Coleman \& Coleman, 2019), consciously and accurately identifying the reflective emotional states it induces as learnable skills. Mindfulness is geared towards facilitating a deep meditative reflection that encourages individuals to encounter and categorize their thoughts in particular ways, detaching oneself from, and then paying attention to, the specific patterns of sensation that they produce (Ivtzan, 2020). Mindfulness seeks to cultivate an awareness of what the mind is doing in the present moment, along with the skill of interrupting unwanted or unhelpful thought patterns, and some have argued that it promises a healthier life, improved relationships with others and better adaptability to one's environment (Coleman \& Coleman, 2019; Davis \& Hayes, 2011). The new perspectives generated by this creative work emerge without making any change whatsoever to the field itself. Rather, the creativity of the practice resides in its transcendence, in the actor moving deeply into a field in order to reinterpret it, emerging with a new outlook on a world that remains precisely as the actor left it.

The creative practice of mindfulness may also overlap with the concept of happiness in some ways, but here its creativity again takes a different form. Mindfulness is increasingly deployed in developed societies as a strategy for achieving a manageable if temporary equilibrium with one's environment where that environment is rapidly changing or unstable, and without actually acting upon the environment itself. Examples of this include the use of mindfulness techniques as regular interventions to reduce work stress in high-pressure workplaces (Bostock et al., 2019), or to reduce perfectionism and foster emotional wellbeing in highly gifted young people (OltonWeber et al., 2020). This approach to creativity is thus not about embracing institutionalized 
cultural practices or voluntary risk-taking at the edge of a field. It is, rather, about giving up old meanings in order to gain new ones, as by-products of being totally involved in a field, perhaps through immersion in creative arts or musical practice, or other forms of work. Emotion as cultural transcendence may thus take many forms and names in different contexts, but the underlying features described here point to a skilled and practiced cultivation of physiological and psychological states that facilitate deep reflection and immersion in a field leading to new interpretations of that field.

\section{Emotion as cultural transformation}

Emotions may take the form of practices aimed at recreating the field in which they occur, by acting creatively upon that field. For Lippens (2012), practices of this nature (his Radical Sovereignty Type 3) represent a more promising bid for sovereignty than the other two types described above, because they are "about creation... it is to bring newness into the world. But in order to be able to do that, that is, to be able to create new law, new code, one must engage with the law or code that is" (p. 354, italics in original). In this process, old forms of oppression are crushed by embracing the field as it exists and reworking it to bring about change. Emotion as practice may thus do creative work by cultivating specific physiological and psychological states in actors through organized social action aimed at bringing about cultural transformation of a field.

The emotion "pride" and its potential for happiness may provide a good example. Viewed from the perspective of emotion as practice, "gay pride" can be understood not as a fundamentally internal physiological or psychological state that same-sex attracted or gayidentifying people may occasionally find themselves to be in, but rather as organized social action aimed at mobilizing, naming, communicating and regulating such states in community members for specific (e.g. social or political) purposes. Steven Kates and Russell Belk's (2001) four-year long ethnographic work on Lesbian and Gay Pride Day (LGPD), using data mainly gathered at the Toronto celebrations, found that the events served as "a complex, multilayered form of consumption-related cultural resistance that raises awareness of social injustice and discursively informs social meanings in everyday life outside the festival" (p. 393). This was partly because conspicuous consumption during the events, which on the one hand may be considered a politically dubious activity, also acted as a "display and show of market power [that] may actually result in social legitimization of the gay and lesbian community" (p. 392). The carnivalesque nature of the events was also linked to specific feeling states, described as "an unusually overwhelming and captivating experience in [participants'] lives" (p. 404). One participant stated,

The first LGPD I experienced ... it was warm, beautiful, wonderful, you know, all the superlatives you can think of. I remember it as being as idealistic as anything I had ever hoped for (laughs), people laughing, hugging each other, kissing, just crowds of gay men and lesbians everywhere. It was definitely one of the biggest highs of my life, that first one (Kates \& Belk, 2001, p. 404).

Forms of participation in the events included "many public and private ritual behaviors" including gift giving, special meals and foods, memorial ceremonies, and "public display by participants in colorful and sometimes outrageous 'gay apparel' (e.g., drag, leather, tight shorts, and T-shirts)", which contributed to the events becoming "a contested social space, [whose] meanings are actively negotiated - and reflexively fought over-in the course of its practice" (p. 
394). By grasping and working with the field as it is - its spaces, languages, products and their meanings (i.e., its laws and codes) - pride, when viewed as emotion as practice, does creative work in this context as cultural transformation by recreating the very field in which it occurs. And, pride may also be linked without too much strain to the notion of happiness through the attendant concepts of fulfilment and contentment (McKenzie, 2016, p. 80), meaning that happiness has, at least tangentially, taken on yet more nuances in the current study, as an active socially and politically driven emotion which exists as organized, creative social action.

\section{Conclusion}

This article opened by reflecting on Vlad Glăveanu's claim that the power of creativity lies in its capacity to reposition people in relation to one another and to the here and now of experience (Glăveanu, 2020b). It has argued that emotions, when viewed from the perspective of emotion as practice (Scheer, 2012), do this work precisely because emotions are, at a fundamental level, creative acts, as Chan's (2016) framework for the sociology of creativity helps to demonstrate. The article has argued that because understanding emotion requires examination not just of selfreported or otherwise observed physiological or psychological states (including neuronal brain states), but examination of the complete picture of the practice by which those states are induced, named, communicated, and regulated, emotion as practice thus affords multiple points of intersection with the sociology of creativity, which illuminates how emotions generate different types of meaningful change and thus do creative work. Emotion as creative practice can be viewed as an embodied and performed act of thought, dynamically linking the feelings and sensations of the body with the body's environment through practices, which, because of the always-imperfect alignment between habitus and field, are both skillfully improvised and also driven by the generative power of habituated tendencies.

This approach has implications for emotions historians, because it proposes a new explanation of the role of emotion in generating historical change. Scheer's (2012) argument about how emotion as practice generates historical change hinged on the "plurality of practices", since practices can "collide with one another, causing misunderstandings, conflicts, and crossovers between fields" (p. 204). This point is insightful, but it does not account for the inherent creativity of emotional practices which this article has sought to identify. Emotions may generate change because they can take the form of institutionalized cultural practice, where individual normative emotional performances are gradually refined and measured against domain-specific standards of excellence which are themselves also gradually shifting. Additionally, emotions may take the form of cultural revolt, where change is wrought by emotional practices as a) cultural edgework at the boundaries between fields; b) cultural transcendence, facilitating new perspectives on an unchanged field; or c) cultural transformation, where an emotional practice grasps and transforms the field itself. Accordingly, historians working with the framework of emotion as practice may be encouraged to refract their line of inquiry in one or more of these creative directions in order to provide a more nuanced explanation of the role of emotion in generating social and historical change.

This approach also has implications for understanding the links between emotion, creativity and individual agency, which can be seen to coalesce in the concept of wellbeing. Emotion as creative practice suggests that emotions entail creative decisions involving varying degrees of intentionality which are shaped in part by internalized moral frameworks. This is pertinent since eminent creativity scholars such as Arthur Cropley have argued that "in defining creativity moral issues should come first" (Cropley, 2011, p. 367); in a similar vein, emotions scholars such as Dixon (2003; 2012) have argued that emotions research could benefit from stronger links 
between psychology, philosophy and ethics. Chan's (2016) sociology of creativity thus helps to explain not only how creativity is central to all social action, but also how its different forms suggest different kinds of links between emotion as practice and a range of moral and ethical concerns. Insofar as emotions are things that we do, rather than things that happen to us, as Scheer (2012) argued, then Chan's (2016) creativity framework helps to reveal how the creativity of emotion connects emotion, in different ways, to the ethical and moral implications of social action. The different creative forms of happiness suggested in this article thus illuminate some of the different ethical and moral dimensions of happiness and how these manifest in practice.

This returns us to the question of the link between creativity and wellbeing. Emotion as creative practice challenges the prevailing focus in wellbeing research on the individual over the collective (Oades \& Heazlewood, 2017, p. 9), a focus that is not only supported by psychological approaches to the study of emotion that treat emotions as fundamentally internal and therefore individual experiences (Ekman, 1999), but also by sociological approaches that treat emotions as "responses" to situations (Lively \& Heise, 2014) rather than practical manifestations of the relationship between (or indeed the wrangling of) social structure and individual agency. Just as systems-informed approaches to positive psychology are seeking out broader and more holistic understandings of wellbeing (Kern et al., 2020), the concept of emotion as creative practice encourages us to rethink wellbeing (and especially the sociology of wellbeing) by expanding the analytical focus to include social structure as a component of emotion. This may help to address Derné's (2017) call for the sociology of wellbeing to pay greater attention to the ways people define and experience wellbeing, by suggesting a pathway towards a more profound sociological conception of wellbeing as a collective rather than individual creative achievement.

\section{Acknowledgements}

This work was supported by the Australian Research Council Centre of Excellence for the History of Emotions [CE1101011] and the Creativity and Wellbeing Hallmark Research Initiative (CAWRI) at the University of Melbourne.

\section{Conflict of interest statement}

The author reports no conflicts of interest.

\section{Authors}

Frederic Kiernan

University of Melbourne

kiernanf@unimelb.edu.au

\section{Publishing Timeline}

Received 2 September 2020

Accepted 26 November 2020

Published 17 December 2020

\section{References}

Agawu, V. K. (1988). Music in the funeral traditions of the Akpafu. Ethnomusicology, 32(1), 75-105. https://doi.org/10.2307/852226

Ahmed, S. (2010). Killing joy: Feminism and the history of happiness. Signs: Journal of Women in Culture $\mathcal{E}$ Society 35(3), 571-592. https://doi.org/10.1086/648513

Averill, J. R. (1999). Individual differences in emotional creativity: Structure and correlates. Journal of Personality 67(2), 331-371. https://doi.org/10.1111/1467-6494.00058 
Averill, J. R. (2009). Emotional creativity: Toward “spiritualizing the passions". In C. R. Snyder \& S. J. Lopez (Eds.), Handbook of positive psychology (2nd ed., pp. 249-258). Oxford University Press. https://doi.org/10.1093/oxfordhb/9780195187243.013.0023

Averill, J. R., \& Nunley, E. P. (1988). Grief as an emotion and as a disease: A social-constructionist perspective. Journal of Social Issues 44(3), 79-95. https://doi.org/10.1111/j.1540-4560.1988.tb02078.x

Baas, M. (2019). In the mood for creativity. In J. C. Kaufman \& R. J. Sternberg (Eds.), The Cambridge handbook of creativity (2nd ed., pp. 257-272). Cambridge University Press.

Barclay, K. (2011). Love, intimacy and power: Marriage and patriarchy in Scotland, 1650-1850. Manchester University Press.

Barclay, K. (2016). Grief, faith and eighteenth-century childhood: The Doddridges of Northampton. In K. Barclay, K. Reynolds, \& C. Rawnsley (Eds.) Death, emotion and childhood in premodern Europe (pp. 17389). Palgrave Macmillan UK. https://doi.org/10.1057/978-1-137-57199-1_9

Barclay, K. (2017). Introduction: Emotions and change. Emotions: History, Culture, Society 1(2), 1-9. https://doi.org/10.1163/2208522X-00102002

Bergen, B. K. (2012). Louder than words: The new science of how the mind makes meaning. Basic Books.

Biess, F. \& D. M. Gross. (2014). Science and emotions after 1945: A transatlantic perspective. University of Chicago Press.

Boddice, R. (2018). The history of emotions. Manchester University Press

Boddice, R. (2019). A history of feelings. Reaktion Books.

Bostock, S., Crosswell, A.D., Prather, A.A. \& Steptoe, A. (2019). Mindfulness on-the-go: Effects of a mindfulness meditation app on work stress and well-being. Journal of Occupational Health Psychology 24(1), 127-138. https://doi.org/10.1037/ocp0000118

Bourdieu, P. (1977). Outline of a theory of practice (R. Nice, Trans.). Cambridge University Press.

Bourdieu, P. (1986). The forms of capital. In J. G. Richardson (Ed.), Handbook of theory and research for the sociology of education (pp. 241-258). Greenwood.

Bourdieu, P. (1990). The logic of practice (R. Nice, Trans.). Stanford University Press.

Brown, T. (1820/2010). Thomas Brown: Selected philosophical writings (T. Dixon, Ed.). Imprint Academic.

Burkitt, I. (1997). Social relationships and emotions. Sociology 31(1), 37-55. https://doi.org/10.1177/0038038597031001004

Chan, J. (2016). Creativity and culture: A sociological perspective. In V. Glăveanu (Ed.), The Palgrave handbook of creativity and culture research (pp. 639-660). Palgrave Macmillan. https://doi.org/10.1057/978-1-137-46344-9_31

Chemero, A. (2009). Radical embodied cognitive science. MIT Press.

Coleman, C. N. \& Coleman, K. F. (2019). Mindfulness for the high performance world: A practical, skillbased approach to developing and sustaining mindfulness, equanimity and balance. Springer. https://doi.org/10.1007/978-3-030-18582-4

Connolly, F. F. \& Sevä, I. J. (2018). Social status and life satisfaction in context: A comparison between Sweden and the USA. International Journal of Wellbeing 8(2), 110-134. https://doi.org/10.5502/ijw.v8i2.710

Cropley, A. (2011). Definitions of creativity. In M. A. Runco \& S. R. Pritzker (Eds.), Encyclopedia of creativity (2nd ed, pp. 358-368). Elsevier. https://doi.org/10.1016/B978-0-12-375038-9.00066-2

Csikszentmihalyi, M. (2014). Flow and the foundations of positive psychology: The collected works of Mihaly Csikszentmihalyi. Springer. https://doi.org/10.1007/978-94-017-9088-8

Dalton, B. (2004). Creativity, habit, and the social products of creative action: Revising Joas, incorporating Bourdieu. Sociological Theory 22(4), 603-622. https://doi.org/10.1111/j.0735-2751.2004.00236.x

Davis, D. M., \& Hayes, J. A. (2011). What are the benefits of mindfulness? A practice review of psychotherapy-related research. Psychotherapy 48 (2), 198-208. https://doi.org/10.1037/a0022062

Davison, K., Jalava, M., Morosini, G., Scheer, M. Steenbergh, K., van der Zande, I. \& Zwicker, L. F. (2018). Emotions as a kind of practice: Six case studies utilizing Monique Scheer's practice-based approach to emotions in history. Cultural History 7(2), 226-238. https://doi.org/10.3366/cult.2018.0175

Derné, S. (2017). Sociology of well-being: Lessons from India (1 ${ }^{\text {st }}$ ed.). SAGE. 
Diener, E. 2009. Subjective well-being. In E. Denier (Ed.), The science of well-being: The collected works of Ed Diener (pp. 11-58). Springer. https://doi.org/10.1007/978-90-481-2350-6_2

Dixon, T. (2003). From passions to emotions: The creation of a secular psychological category. Cambridge University Press. https://doi.org/10.1017/CBO9780511490514

Dixon, T. (2012). "Emotion": The history of a keyword in crisis. Emotion Review 4, 338-344. https://doi.org/10.1177/1754073912445814

Dodge, R., Daly, A. P., Huyton, J \& Sanders, L D. (2012). The challenge of defining wellbeing. International Journal of Wellbeing 2(3), 222-235. https://doi.org/10.5502/ijw.v2i3.4

Domingues, J.M. (2000). Creativity and master trends in contemporary sociological theory. European Journal of Social Theory 3(4), 467-484. https://doi.org/10.1177/13684310022224903

Dubois, J. (2000). Pierre Bourdieu and literature (M. Emery \& P. V. Sing, Trans). SubStance 29(3), 84-102. https://doi.org/10.1353/sub.2000.0028

Ehrenreich, B. (2010). Smile or die: How positive thinking fooled America and the world. Granta Books.

Eitler, P., Hitzer, B. \& Scheer, M. (2014). Feeling and faith - Religious emotions in German history. German History 32(3), 343-352.

Ekman, P. (1999). Basic emotions. In T. Dalgleish \& M. Power (Eds.), Handbook of cognition and emotion (pp. 45-60). John Wiley \& Sons.

Ekman, P. (2007). Emotions revealed: Recognizing faces and feelings to improve communication and emotional life. (2nd ed). St. Martin's Griffin.

Ekman, P. \& Friesen, W. V. (1971). Constants across cultures in the face and emotion. Journal of Personality and Social Psychology 17(2), 124-129. https://doi.org/10.1037/h0030377

Ekman, P. E., Sorenson, R. and Friesen, W. V. (1969). Pan-cultural elements in facial displays of emotion. Science 164(3875), 86-88. https://doi.org/10.1126/science.164.3875.86

Erickson, R. J. \& Cottingham., M. D. (2014). Families and emotions. In J. E. Stets \& J. H. Turner (Eds.) Handbook of the sociology of emotions: Volume II (pp. 359-383). Springer Netherlands. https://doi.org/10.1007/978-94-017-9130-4_17

Ewert, A. W. (1994). Playing the edge: Motivation and risk taking in a high-altitude wilderness like environment. Environment and Behavior 26(1), 3-24. https://doi.org/10.1177/0013916594261001

Frevert, U., Eitler, P., Olsen, S., Jensen, U., Pernau, M., Brückenhaus, D., Beljan, M., Gammerl, B., Laukötter, A, Hitzer, B., Plamper, J., Brauer, J., \& Häberlen, J. C. (Eds.). (2014). Learning how to feel: Children's literature and emotional socialization, 1870-1970. Oxford University Press.

Fujishiro, K., Xu, J. and Gong. F. (2010). What does "occupation” represent as an indicator of socioeconomic status?: Exploring occupational prestige and health. Social Science $\mathcal{E}$ Medicine 71(12), 2100-2107. https://doi.org/10.1016/j.socscimed.2010.09.026

Gallagher, S. (2005). How the body shapes the mind. Oxford University Press. https://doi.org/10.1093/0199271941.001.0001

Glăveanu, V. P. (2014). Distributed creativity: Thinking outside the box of the creative individual. Springer. https://doi.org/10.1007/978-3-319-05434-6

Glăveanu, V. P. (2015). Creativity as a sociocultural act. The Journal of Creative Behavior 49(3), 165-180. https://doi.org/10.1002/jocb.94

Glăveanu, V. P. (2020a). Mobilities and human possibility. Palgrave Macmillan. https://doi.org/10.1007/9783-030-52082-3

Glăveanu, V. P. (2020b). Creativity on the move. MIC [Marconi Institute for Creativity] Conference 2020: Nurturing creative potential. Bologna.

Griffiths, P. E., \& Scarantino, A. (2009). Emotions in the wild: The situated perspective on emotion. In P. Robbins and M. Aydede (Eds.), Cambridge handbook of situated cognition. Cambridge University Press.

Harkness, S. K., \& Hitlin, S. (2014). Morality and emotions. In J. E. Stets \& J. H. Turner (Eds.), Handbook of the sociology of emotions: Volume II (pp. 451-471). Springer Netherlands. https://doi.org/10.1007/978-94017-9130-4_21

Henderson, L. W. \& Knight, T. (2012). Integrating the hedonic and eudaimonic perspectives to more comprehensively understand wellbeing and pathways to wellbeing. International Journal of Wellbeing 2(3), 196-221. https://doi.org/10.5502/ijw.v2i3.3 
Hess, U. (2017). Emotion categorization. In H. Cohen \& C. Lefebvre (Eds.), Handbook of categorization in cognitive science (2nd ed., pp. 107-126). Elsevier Science. https://doi.org/10.1016/B978-0-08-1011072.00005-1

Hochschild, A. R. (1983). The managed heart: Commercialization of human feeling. University of California Press.

Huta, V. (2016). An overview of hedonic and eudaimonic well-being concepts. In L. Reinecke \& M. B. Oliver (Eds.), The Routledge handbook of media use and well-being: International perspectives on theory and research on positive media effects (pp. 14-33). Routledge.

Isen, A. M., Nowicki, G. P. \& Daubman, K.A. (1987). Positive affect facilitates creative problem solving. Journal of Personality E Social Psychology 52(6), 1122-1131. https://doi.org/10.1037/0022-3514.52.6.1122

Ivcevic, Z. \& Hoffmann, J. (2017). Emotions and creativity: From states to traits and emotion abilities. In G. J. Feist, R. Reiter-Palmon, and J. C. Kaufman (Eds.) The Cambridge handbook of creativity and personality research (pp. 187-213). Cambridge University Press. https://doi.org/10.1017/9781316228036.011

Ivcevic, Z. \& Hoffmann, J. (2019). Emotions and creativity: From process to person and product. In J. C. Kaufman and R. J. Sternberg (Eds.), The Cambridge handbook of creativity (2nd ed., pp. 273-295).

Cambridge University Press. https://doi.org/10.1017/9781316979839.015

Ivtzan, I., (Ed.). (2020). Handbook of mindfulness-based programmes: Mindfulness interventions from education to health and therapy. Routledge. https://doi.org/10.4324/9781315265438

Izard, C. E. (2010). The many meanings/aspects of emotion: Definitions, functions, activation, and regulation. Emotion Review 2(4), 363-370. https://doi.org/10.1177/1754073910374661

Jalland, P. (1996). Death in the Victorian family. Oxford University Press. https://doi.org/10.1093/acprof:oso/9780198201885.001.0001

James, W. (1884). What is an emotion? Mind 9: 188-205. https://doi.org/10.1093/mind/os-IX.34.188 Joas, H. (1996). The creativity of action (J. Gaines \& P. Keast, Trans.). University of Chicago Press.

Kahneman, D., Diener, E., \& Schwarz, N. (1991). Foundations of hedonic psychology: Scientific perspectives on enjoyment and suffering. Russell Sage Foundation.

Kates, S. M., and Belk, R. W. (2001). The meanings of lesbian and gay pride day: Resistance through consumption and resistance to consumption. Journal of Contemporary Ethnography 30(4), 392-429. https://doi.org/10.1177/089124101030004003

Kern, M. L., Williams, P., Spong, C., Colla, R., Sharma, K., Downie, A., Taylor, J. A., Sharp, S., Siokou, C., \& Oades, L. G. (2020). Systems informed positive psychology. The Journal of Positive Psychology, 15(6), 705-715. https://doi.org/10.1080/17439760.2019.1639799

Kimmel, M., Hristova, D., \& Kussmaul, K. (2018). Sources of embodied creativity: Interactivity and ideation in contact improvisation. Behavioral Sciences 8(6) 1-37. https://doi.org/10.3390/bs8060052

Kleinginna, P. R., \& Kleinginna, A.M. (1981). A categorized list of emotion definitions, with suggestions for a consensual definition. Motivation and Emotion 5(4), 345-379. https://doi.org/10.1007/BF00992553

Lippens, R. (2012). Control over emergence: Images of radical sovereignty in Pollock, Rothko, and Rebeyrolle. Human Studies 35(3), 351-364. https://doi.org/10.1007/s10746-012-9237-x

Lively, K. J., \& Heise, D. R. (2014). Emotions in affect control theory. In J. E. Stets \& J. H. Turner (Eds.), Handbook of the sociology of emotions: Volume II (pp. 51-75). Springer Netherlands. https://doi.org/10.1007/978-94-017-9130-4_4

Lively, K. J., \& Weed, E. A. (2016). The sociology of emotion. In L. F. Barrett, M. Lewis, \& J. M. HavilandJones (Eds.), Handbook of emotions (4th ed., pp. 66-81). Guilford Publications.

Lutz, C. (1988). Unnatural emotions: Everyday sentiments on a Micronesian atoll \& their challenge to Western theory. University of Chicago Press. https://doi.org/10.7208/chicago/9780226219783.001.0001

Lyng, S. (1990). Edgework: A social psychological analysis of voluntary risk taking. American Journal of Sociology 95(4), 851-886. https://doi.org/10.1086/229379

Lyubomirsky, S. \& Lepper, H. S. (1999). A measure of subjective happiness: Preliminary reliability and construct validation. Social Indicators Research 46(2), 137-155. https://doi.org/10.1023/A:1006824100041

Maiello, G. (2005). Současné pohřební rituály v českých zemích na př́kladu krematorií v PrazeStrašnicích, Zlíně a Plzni. Český lid, 92(1), 35-47. 
Maton, K. (2014). Habitus. In M. J. Grenfell (Ed.), Pierre Bourdieu: Key concepts (2nd ed., pp. 48-64). Routledge.

McKenzie, J. (2016). Deconstructing happiness: Critical sociology and the good life. Routledge. https://doi.org/10.4324/9781315735931

McMahon, D. M. (2006). Happiness: A history. Atlantic Monthly Press.

Moore, R. (2014). Capital. In M.J. Grenfell (Ed.), Pierre Bourdieu: Key concepts (2nd ed., pp. 98-113). Routledge.

Oades, L.\& Heazlewood, F. (2017). Wellbeing language \& definitions guide. Sydney: Mental Health Commission of NSW. https://wbcnsw.files.wordpress.com/2017/09/language-and-definitions-guideweb.pdf

Oiyama, T. (2013). Dochaku: Artistic evolution at the confluence of cultures. In K. Thomas \& J. Chan (Eds.), Handbook of research on creativity (pp. 408-21). Edward Elgar Publishing. https://doi.org/10.4337/9780857939814.00040

Olton-Weber, S., Hess, R. \& Ritchotte, J. A. (2020). Reducing levels of perfectionism in gifted and talented youth through a mindfulness intervention. Gifted Child Quarterly 64(4), 319-330. https://doi.org/10.1177/0016986220953392

Paul, E. S., \& Kaufman, S. B. (Eds.). (2014). The philosophy of creativity: New essays. Oxford University Press. https://doi.org/10.1093/acprof:oso/9780199836963.001.0001

Plamper, J. (2015). The history of emotions: An introduction. Oxford University Press.

Racy, A. J. (1986). Lebanese laments: Grief, music, and cultural values. The World of Music, 28(2), 27-40.

Radford, M. (2004). Emotion and creativity. Journal of Aesthetic Education 38(1), 53-64. https://doi.org/10.2307/3527362

Reddy, W. M. (2001). The navigation of feeling: A framework for the history of emotions. Cambridge University Press. https://doi.org/10.1017/CBO9780511512001

Reddy, W. M. (2008). Emotional styles and modern forms of life. In N. C. Karafyllis \& G. Ulshöfer (Eds.), Sexualized brains: Scientific modeling of emotional intelligence from a cultural perspective (pp. 81-100). MIT Press.

Rehn, A., \& De Cock, C. (2009). Deconstructing creativity. In T. Rickards, M. A. Runco, \& S. Moger (Eds.), The Routledge companion to creativity (pp. 222-231). Routledge. https://doi.org/10.4324/9780203888841

Rhodes, M. (1961). An analysis of creativity. The Phi Delta Kappan 42(7), 305-310.

Robbins, D. (2014). Theory of practice. In M. J. Grenfell (Ed.), Pierre Bourdieu: Key concepts (2nd ed., pp 2640). Routledge.

Rogers, C. (1961). On becoming a person. Houghton-Mifflin.

Rosaldo, M. (1980). Knowledge and passion: Ilongot notions of self and social life. Cambridge University Press. https://doi.org/10.1017/CBO9780511621833

Rosenblatt, P. C. (2004). Grieving while driving. Death Studies 28(7), 679-686. https://doi.org/10.1080/07481180490476533

Rosenwein, B. H. (2006). Emotional communities in the early Middle Ages. Cornell University Press.

Runco, M. \& Jaeger, G. J. (2012). The standard definition of creativity. Creativity Research Journal 24(1), $92-$ 96. https://doi.org/10.1080/10400419.2012.650092

Russ, S. W. (2020). Emotion/Affect. In M. Runco and S. Pritzker (Eds.), Encyclopedia of creativity (3rd ed., pp. 427-433). Academic Press. https://doi.org/10.1016/B978-0-12-809324-5.21215-7

Russ, S. W. (1993). Affect and creativity: The role of affect and play in the creative process. Erlbaum. https://doi.org/10.4324/9780203772621

Ryan, R. M., \& Deci E. L. (2001). On happiness and human potentials: A review of research on hedonic and eudaimonic well-being. Annual Review of Psychology 52, 141-166.

https://doi.org/10.1146/annurev.psych.52.1.141

Ryan, T. (2019). Coca Cola slogans through the years. Coca Cola Australia. https://www.cocacolacompany.com/au/news/coca-cola-slogans-through-the-years

Ryff, Carol D. (1989). Happiness is everything, or is it? Explorations on the meaning of psychological well-being. Journal of Personality and Social Psychology 57(6), 1069-1081. https://doi.org/10.1037/00223514.57.6.1069 
Ryff, C. D., and Singer, B. H. (2008). Know thyself and become what you are: A eudaimonic approach to psychological well-being. Journal of Happiness Studies 9(1), 13-39. https://doi.org/10.1007/s10902-0069019-0

Schatzki, T. R. (2012). A primer on practices: Theory and research. In J. Higgs, R. Barnett, S. Billett, M. Hutchings, and F. Trede, (Eds.), Practice-based education: Perspectives and strategies (pp. 13-26). Sense Publishers.

Scheer, M. (2012). Are emotions a kind of practice (and is that what makes them have a history)? A Bourdieuian approach to understanding emotion. History and Theory: Studies in the Philosophy of History 51(2), 193-220. https://doi.org/10.1111/j.1468-2303.2012.00621.x

Schultz, E. J. (2019). Apple beats Google for top spot in global brand ranking. AdAge. https://adage.com/article/cmo-strategy/apple-beats-google-top-spot-global-brand-ranking/298769.

Seligman, M. (2002). Authentic happiness: Using the new positive psychology to realize your potential for lasting fulfillment. Simon and Schuster.

Seligman, M. (2011). Flourish: A new understanding of happiness and well-being - and how to achieve them. Nicholas Brealey Publishing.

Smith, J. P. (2004). Unraveling the SES: Health Connection. The Institute for Fiscal Studies, WPO4/02. https://doi.org/10.1920/wp.ifs.2004.0402

Stets, J. E., and Turner, J. H. (Eds.). (2014a). Handbook of the sociology of emotions: Volume II. Springer Netherlands. https://doi.org/10.1007/978-94-017-9130-4_1.

Stets, J. E., and Turner, J. H. (2014b). Introduction. In J. E. Stets \& J. H. Turner (Eds.) Handbook of the sociology of emotions: Volume II (pp. 1-7). Springer Netherlands. https://doi.org/10.1007/978-94-0179130-4_1

Sutton, J., Mcllwain, D. Christensen, W. \& Geeves, A. (2011). Applying intelligence to the reflexes: embodied skills and habits between Dreyfus and Descartes. Journal of the British Society for Phenomenology 42(1), 78-103. https://doi.org/10.1080/00071773.2011.11006732

Thoits, P. A. (1984). Coping, social support, and psychological outcomes: The central role of emotion. Review of Personality \& Social Psychology 5, 219-238.

Thomson, P. (2014). Field. In M. J. Grenfell (Ed.), Pierre Bourdieu: Key concepts (2nd ed., pp., 65-82). Routledge.

Treiman, D. J. (2013). Occupational prestige in comparative perspective. Elsevier.

Trigg, S. (2014). Introduction: Emotional histories - beyond the personalization of the past and the abstraction of affect theory. Exemplaria 26(1), 3-15. https://doi.org/10.1179/1041257313Z.00000000043

Vittersø, J. (Ed.). (2016). Handbook of eudaimonic well-being. Springer. https://doi.org/10.1007/978-3-31942445-3

Waterman, A. S., Schwartz, S. J., Zamboanga, B. L., Ravert, R. D., Williams, M. K., Agocha, B., Kim, S. Y., \& Donnellan, M. B. (2010). The questionnaire for eudaimonic well-being: Psychometric properties, demographic comparisons, and evidence of validity. The Journal of Positive Psychology 5(1), 41-61. https://doi.org/10.1080/17439760903435208 